\title{
Developing a New Picture Archiving and Communication System for the New Osaka University Hospital
}

\author{
Hiroshi Kondoh, Junpei Ikezoe, Kiyonari Inamura, Chikazumi Kuroda, and Takahiro Kozuka
}

\begin{abstract}
Osaka University Hospital moved into a new hospital building on the suburban Suita campus in October 1993. A newly developed hospital information system, a new radiologic information system and phase I of a completely new Picture Archiving and Communication System (PACS) also began operating. Work began in 1986 on this PACS. The PACS effort has been guided by one working group and two committees during the last 7 years. A survey of the previous diagnostic and image delivery system was performed as part of the preamble to designing an optimal PACS. Extensive analysis and measurement of pre-existing operational conditions was undertaken. These studies and technical research projects are described in a companion paper in this issue. The phase I hardware installation and initial testing were completed in March 1994. Subsequent phases will build incrementally until the completely new, hospital-wide PACS is realized.

Copyright 1994 by W.B. Saunders Company
\end{abstract}

KEY WORDS: hospital information system (HIS), radiological information system (RIS), picture archiving and communication system (PACS).

$\mathbf{O}$ SAKA UNIVERSITY Hospital has 1,011 beds with 22 clinical departments and nine service divisions including the central radiology facility of Radiology. The Radiology Department medical imaging equipment is listed in Table 1.

About 120,000 radiologic examinations are performed annually. The volume of radiographic images is about 260,000 sheets of film per year (namely 1,100 sheets per day).

The statistics of volume of radiographic images are expressed as the number of sheets of film because Japanese health insurance pays for imaging procedures on the basis of the number of sheets of film used. There are 600,000 digital images (computed tomography [CT], magnetic resonance imaging [MRI], digital subtraction

From the Department of Radiology, School of Medicine; and the Department of Radiological Technology and Biomedical Engineering, School of Allied Health Sciences, Faculty of Medicine, Osaka University, Osaka, Japan.

Address reprint requests to Hiroshi Kondoh, MD, Department of Radiology, Osaka University Medical School, 2-2, Yamada-oka, Suita, Osaka 565, Japan

Copyright $\oplus 1994$ by W.B. Saunders Company

0897-1889/94/0704-0008\$3.00/0 angiography, and others) processed annually (2,300 digital images per day).

Our goal is to implement a new, hospital-wide picture archiving and communication systems (PACS) in phases with close integration with the new radiological information system (RIS) and hospital information system (HIS). Specific challenges include balancing the speed and resolution of workstations against cost and balancing response time degradation against the number of workstations., ${ }^{1,2}$ Although fast, highcost workstations are needed for acute-care patients, they are not required for research, teaching, nor the large percentage of chronic care patients. ${ }^{2}$ Film-based chest examinations will continue to be available in early phases. ${ }^{2}$

Care will be taken to avoid duplication of RIS and HIS functions initially. To push PACS too strongly would diminish the role of RIS and HIS unwisely. 3,4 What can be done by the HIS and the RIS must not be replaced by PACS. Because PACS is so expensive, it is prudent to initially furnish the results of diagnosis by radiologists via the HIS-transmitted radiologic report only, rather than with the images themselves.

\section{SYSTEM DESIGN}

During the past 7 years, we have studied other PACS projects in Japan and elsewhere. One of the authors of this paper participated in the design and development of the Hokkaido University Hospital PACS (HU-PACS) ., ,3,5-12 All of the authors have visited Hokkaido several times to observe the functions and practical aspects of the HU-PACS operation. Most of the authors also visited the University of California Los Angeles (UCLA) PACS and discussed it with key persons in that institution. ${ }^{2}$ Georgetown University, ${ }^{4}$ the Hospital of the University of Pennsylvania, ${ }^{12}$ Bowman Gray School of Medicine, and other centers in the United States and Europe were also visited. Discussions on site and at international conferences were very helpful.

Based on the published literature and our 
Table 1. Medical Imaging Equipments at the Department of Radiology, Osaka University Hospital

\begin{tabular}{lcc}
\hline & $\begin{array}{c}\text { Previous } \\
\text { Hospital }\end{array}$ & $\begin{array}{c}\text { Present } \\
\text { Hospilal }\end{array}$ \\
\cline { 2 - 3 } General radiography & 5 & 11 \\
CA & 1 & 11 \\
Tomography & 3 & 2 \\
Mammography & 1 & 1 \\
Remote control fluoroscopy & 5 & 5 \\
CT & 3 & 3 \\
Uitrasound (include color doppler) & 4 & 6 \\
MRi & 2 & 3 \\
Angiography system & 2 & 2 \\
Cardiac catheterization system & 1 & 2 \\
Gamma camera (include SPECT) & 5 & 6 \\
\hline
\end{tabular}

visits and discussions, the following conclusions were made part of our PACS design: (1) Experimental PACS and practical hospital-wide PACS are completely different systems. Simple modification or expansion of an experimental PACS is not possible. (2) It is important to design the PACS concurrently or after the RIS and HIS development. (3) The installed number of computed radiography (CR) units influences successful image-data acquisition., ${ }^{1,2}$ (4) Using standard- ized interfaces for image-data acquisition significantly reduces software development costs..$^{13}(5)$ The cost impact of higher-resolution image-display workstations is great. ${ }^{1,2,11}$ (6) Joint Photographic Experts Group (JPEG) 12-bit image data compression appears to be the most promising technology in terms of cost and speed. ${ }^{2}$

Table 2 outlines the history and schedule of the Osaka University PACS project. Development in the following major areas will commence or continue later. Work planned for later phases of the PACS include (1) improvement of the ergonomic workstation design; (2) application of an expert system for diagnosis support; (3) playback of digitized voice reports synchronized with the interpreted images ${ }^{14,15}$; (4) computer-aided diagnosis by means of image processing ${ }^{16}$; (5) adoption of standard interface such as Medical Image Processing System (MIPS) version 3.0, which is the Japanese equivalent of the American College of Radiology/National Electrical Manufacturers Association (ACR-NEMA) DICOM 3.0 ${ }^{16,17}$; (6) continuing assessment of technology ${ }^{18} ;(7)$ continuing

Table 2. The History and Schedule of Development and Technology Assessment of PACS in Osaka University Hospital

\begin{tabular}{|c|c|c|c|}
\hline Year & Evaluztion and Development & Survey & Experimentai PACS \\
\hline 1986 & $\begin{array}{l}\text { Evaluation of stand-alone film digita- } \\
\text { tion, storage, and display }\end{array}$ & $\begin{array}{l}\text { Review of the current medical image } \\
\text { information }\end{array}$ & MediFile-1000 (NEC Corp) \\
\hline 1988 & $\begin{array}{l}\text { Clinical evaluation of high-resolution } \\
\text { storage phosphor system }\end{array}$ & $\begin{array}{l}\text { Start of measurement and analysis of } \\
\text { present medical diagnosis system }\end{array}$ & $\begin{array}{l}\text { Fileace } 4100 \text { (Mitsubishi Co, Tokyo, } \\
\text { Japan), Kodak storage phosphor } \\
\text { system }(4,000 \times 5,000 \times 12 \text { bits; } \\
\text { Eastman-Kodak, Rochester, NY) }\end{array}$ \\
\hline 1989 & $\begin{array}{l}\text { Evaluation and consensus of medical } \\
\text { image quality }\end{array}$ & $\uparrow$ & TDIS (Toshiba Co) \\
\hline 1990 & $\begin{array}{l}\text { Demonstration and consensus in } \\
\text { image quality and speed in the } \\
\text { Hospital }\end{array}$ & $\begin{array}{c}\text { Measurement and analysis of pres- } \\
\text { ent medical diagnostic system }\end{array}$ & \\
\hline 1991 & $\begin{array}{c}\text { Test run of a small PACS, FCR, and } \\
\text { Medifile, to identify problems }\end{array}$ & $\downarrow$ & $\begin{array}{l}\text { FCR (Fuji Film Co, MediFile-500 } \\
\text { (NEC CO) }\end{array}$ \\
\hline 1992 & $\begin{array}{l}\text { System design in detail and software } \\
\text { development }\end{array}$ & & \\
\hline \multirow[t]{3}{*}{1993} & Move to the new hospital & End of the survey & \\
\hline & Start of RIS/HIS operation & $\begin{array}{l}\text { Preparation for technology assess- } \\
\text { ment }\end{array}$ & \\
\hline & Start of new PACS installation & & \\
\hline 1994 & Start of new PACS operation & The survey of the new PACS & \\
\hline 1995 & Link to RIS and HIS & & \\
\hline 1996 & Full-size PACS operation & $\begin{array}{l}\text { Comparison of data before and after } \\
\text { PACS adjustment and completion } \\
\text { of technology assessment }\end{array}$ & \\
\hline 1997 & & & \\
\hline
\end{tabular}

Abbreviation: JDIS, Toshiba Digital Jmage System 
evaluation of cathode ray tube (CRT) screen ${ }^{16}$ image quality; (8) faster image-display response; and (9) improvement ease of use of image-display workstations.

The first meeting to discuss PACS for the new Osaka University Hospital was held in 1986. It was concluded that implementation of a PACS would have merit in long-time storage, image processing, image transmission, image management, education, and computer-aided diagnosis. On the other hand, image quality, the large size of the system, the time interval between expense outlay and having an operating system, and transmission time were recognized as problems.

In 1987 The Medical Information Science Department of Osaka University Hospital started the official development of the total information system for the new hospital. Seven working groups were established including order entry, ward administration system, outpatient clinic system, system for pharmaceutical prescribing, medical-history storage module, resource supply system, and RIS/PACS.

The RIS/PACS working group included surgeons, physicians, clerks, and radiologists. Its aim is to understand the needs of other departments of the hospital for images. Meetings have been held once every 2 or 3 months. The working group decided to begin with radiologic images and later to gradually include endoscopic and pathologic images.

Two local committees were formed. The first was composed of radiologists, radiologic technologists and nurses in the Radiology Department. Its aim is to clarify departmental needs. A small experimental PACS (MediFile-1000 of NEC Corp, Tokyo, Japan) was installed to demonstrate PACS to committee members. The group has met about once every 3 months.

A second local committee was charged with the system design and with developing and evaluating software and hardware. In addition to radiologists, technologists, medical physicists, and engineers from the College of Biomedical Technology of Osaka University, engineers from companies such as NEC Corp were included as members. Also, we had cooperative research projects assisted by the Japanese Government for an experimental high-resolution storage phosphor system with Eastman-Kodak

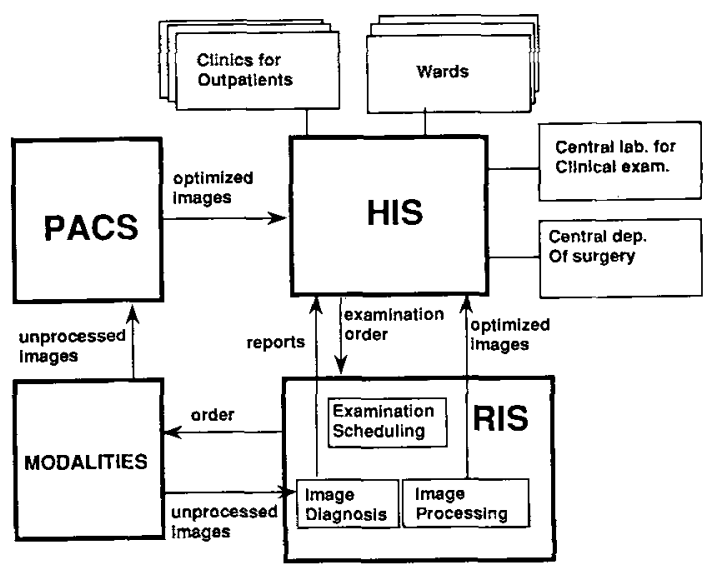

Fig 1. The design of PACS for Osaka University Hospital. PACS is operated closely with RIS and HIS.

(Rochester, NY) and for an experimental RIS and small PACS with Toshiba Co (Tokyo, Japan). Meetings with NEC Corp (a computer system developer; Tokyo, Japan) occur at least once a month. Frequent meetings with Fuji Film Co (Tokyo, Japan) are held to develop effective storage phosphor systems for the PACS environment. Diagnostic equipment manufacturers have participated sometimes in these meetings to develop the interface between the PACS and the RIS and their equipment. The frequency of meetings of this committee accelerated to many times a month toward the end of 1992 to discuss evaluation results and system design issues.

A survey of all departments of the hospital as

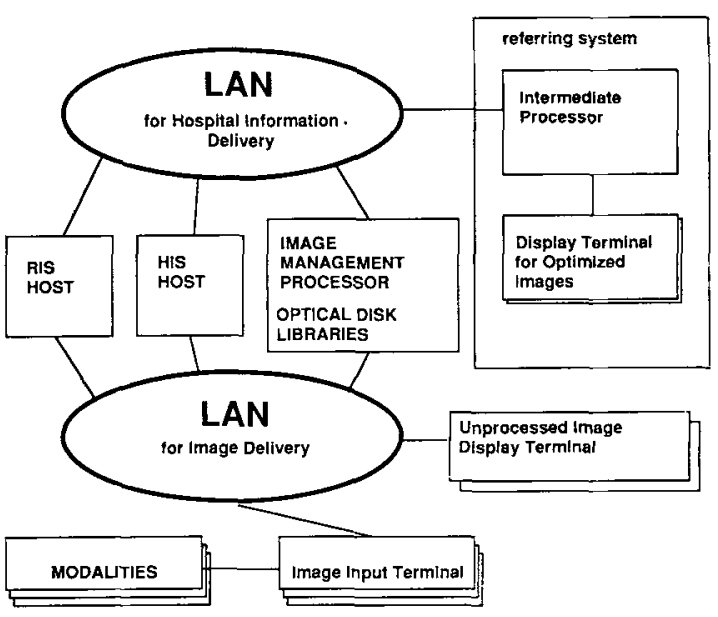

Fig 2. The design of hardware configuration for PACS, RIS, and HIS of Osaka University Hospital. 


\begin{tabular}{|c|c|c|}
\hline & & $\begin{array}{c}\text { No. of } \\
\text { Machines } \\
\text { Installed }\end{array}$ \\
\hline \multicolumn{3}{|l|}{ HIS } \\
\hline Host & ACOS3600/10MP (NEC Co. Tokyo) & 1 \\
\hline Server & EWS4800(NEC Corp) & 55 \\
\hline \multicolumn{3}{|c|}{$\begin{array}{l}\text { HIS terminal for doctors, nurses, } \\
\text { and technicians }\end{array}$} \\
\hline & & 482 \\
\hline & 1) PC-98 Mate (CPU: i 486,66 or $33 \mathrm{MHz}, \mathrm{RAM}: 14.6$ Mbyte) (NEC Corp) & \\
\hline & 2) Branch 4680 Ethernet board & \\
\hline HIS terminal for clerks & S3100/X5(NEC Corp) & 66 \\
\hline \multicolumn{3}{|l|}{ RIS/PACS } \\
\hline RIS server & EWS4800/350(NEC Corp) & 3 \\
\hline PACS server & EWS4800/350 + jukebox type optical disk unit + HD + magnetic tape & 3 \\
\hline \multicolumn{3}{|c|}{$\begin{array}{l}\text { RIS terminal/PC-IDT } \\
\text { (personal computer-image display } \\
\text { terminal) }\end{array}$} \\
\hline & & 58 \\
\hline & 1) PC-98 Mate (CPU: i $48666 \mathrm{MHz}$, RAM: 14.6 Mbyte) (NEC Corp) & \\
\hline & 2) 12-bit JPEG compression-decompression board (25) & \\
\hline & 3) Branch 4680 Ethernet board & \\
\hline \multicolumn{3}{|c|}{ Modality interface terminal } \\
\hline & & 17 \\
\hline & 1) PC98 Mate (CPU: i486 66MHz, RAM: 14.6 Mbyte) (NEC Corp) & \\
\hline & 2) 12-bit JPEG compression-decompression board & \\
\hline & 3) Branch 4680 Ethernet board & \\
\hline & 4) Image input I/F & \\
\hline & DR11/W-FCR, IIDR, Konica film scanner (film digitize) & \\
\hline & $\begin{array}{l}\text { Ethernet-YMS (Tokyo, Japan) DATAVIEW, Toshiba CT, Hitachi } \\
\text { (Tokyo, Japan) WS (nuclear medicine) }\end{array}$ & \\
\hline & RS-422-Konica laser printer (MRI) & \\
\hline
\end{tabular}

Abbreviations: RAM, random access memory; $H D$, hard drive; $1 / F$, interface.

to what kind of medical images would be used at the new hospital was done.

Responses to the question of what kind of medical image information should be sent to the outpatient clinics were as follows: report only, $2 \%$; CRT image and report, $60 \%$; and conventional screen film radiographs and report, $38 \%$.

Responses to the same question for inpatient wards were as follows: report only, 0\%; CRT image and report, $60 \%$; and conventional screen film radiographs and report, $40 \%$.

This survey disclosed that $60 \%$ of the physicians would be satisfied with CRT images instead of conventional radiographs. However, there was a major hidden problem; physicians did not necessarily know the details of the new system, particularly the image quality of the planned CRT display. Nevertheless, it appeared that there were no serious obstacles to obtaining consensus to introduce PACS into our hospital. In addition, the background of PACS in Japan seemed to be on our side. ${ }^{14,15,18}$

The concept used in the system design of the PACS for Osaka University Hospital began with careful quantitative measurement of all aspects of present image-based operations. The analysis of these studies was then used in designing the new PACS for assessing technology to be incorporated in it and subsequently for assessing the effectiveness of the PACS. The many specific studies of the current situation that were done are described in a companion paper. Also described briefly in that paper are the stand-alone PACS MediFile-1000, the small PACS TDIS, and three other technology research projects done as part of the system design and technology assessment.

\section{PACS CONFIGURATION}

The PACS will be closely integrated with the RIS and HIS. The configuration is shown in Figs 
1 and 2. Phase I operation began in October 1993, and was completed by March 1994 (Table 3).

Two classes of terminals are shown in Fig 2. The first class of PACS terminals is for display of "optimized images." They will be installed in many clinics and in wards together with HIS terminals or RIS terminals. Notification of the availability of the "optimized images" will be sent to the HIS together with the radiologic report. Requests to display images with the radiologic report will be made through the HIS via the local area network. The second, higher- resolution group will handle "standard unprocessed images" for diagnosis by radiologists. The "standard unprocessed images" (Fig 1) will be routed to these higher image-quality workstations from modalities such as CR, CT, MRI and from film digitizers. The 7 years of effort have resulted in what appears to be a robust system design. Its flexibility allowed for some reprogramming recently to accommodate revised workstation hardware. Although it is still early in the introduction of the PACS operation, it is hoped that the overall result will be most useful.

\section{REFERENCES}

1. Ozaki Y, Miyasaka K: Image terminal series of Hokkaido University picture archiving communication system. J Digit Imaging 4:15-19, 1991 (Suppl 1)

2. The UCLA PACS research and development program and related projects-A progress report. Los Angeles, CA, Department of Radiological Sciences, UCLA, 1991

3. Takeda I, Kido T: Network system: The integrated picture archiving and communication system with the hospital information system. J Digit Imaging 4:3-14, 1991 (Suppl 1)

4. Horii SC, Horii HN, Mun SK, et al: Environmental design for reading from imaging work stations: Ergonomic and architectual features. J Digit Imaging 2:156-162, 1989

5. Terae S, Miyasaka K, Fujita N, et al: Compression of the digitized $\mathrm{x}$-ray images-Evaluation of compression ratio and image quality allowed in clinical use. Nippon Act Radiol 47:1189-1197, 1987

6. Irie G: Concept of Hokkaido University picture archiving communication System. J Digit Imaging 4:3-5, 1991 (Suppl 1)

7. Asai E, Takano M, Chida M: FCR system in Hokkaido University Hospital. J Digit Imaging 4:20-23, 1991 (Suppl 1)

8. Yamamoto I, Kaneda K: The practical use and evaluation of picture archiving and communication system in the department of orthopaedic surgery. J Digit Imaging 4:25-27, 1991 (Suppl 1)

9. Miyamoto K, Abe S, Kawakami Y: Picture archiving and communication system in Hokkaido University Hospital: Advantage and disadvantage of HU-PACS chest roentogenogram images in the outpatient clinic. J Digit Imaging 4:28-31, 1991 (Suppl 1)
10. Miyasaka K, Abe S, Fujita N, et al: Management and clinical utilization of computed tomography, magnetic resonance imaging, and angiography in Hokkaido University Hospital picture archiving and communication system. J Digit Imaging 4:32-35, 1991 (Suppl 1)

11. Bauman RA, Taaffe JL: Evolution of picture archiving and communication systems-1989. J Digit Imaging 4:37-42, 1991 (Suppl 1)

12. Kundel HL, Seshadri SB, Carey B, et al: Display station utilization in a PACS serving the medical intensive care unit of the Hospital of the University of Pennsylvania. SPIE Proc 1654:424-427, 1992

13. Chimiak WJ: Performance of image communications using TCP/IP, XTP, and Ethernet. SPIE Proc 1654:278288,1992

14. Inamura K: PACS in Japan, in: Proceedings of the Computer-Assisted Radiology Meeting. Berlin, Germany, Springer-Verlag, 1991, pp 383-390

15. Maeda T, Abe M, Akatsuka T: Recognition of PACS in Japan: Proceedings IMAC '91. Los Alamos, CA, IEEE Computer Society, 1991, pp 22-28

16. Inamura $\mathrm{K}$, Umeda $\mathrm{T}$, Takigawa $A$, et al: A Trial of PACS employing magneto-optical disks. SPIE Proc 1234:5058,1990

17. Umeda $T$, Inamura $\mathrm{K}$, Inamoto $\mathrm{K}$, et al: Multi-media PACS integrated with HIS/RIS emplying magneto-optical disk. SPIE Proc 1446:199-210, 1991

18. Inamura K: Basic IMAC Concepts Technology Overview: Proceedings IMAC '91. Los Alamos, CA, IEEE Computer Society, 1989, pp 292-303 